\title{
Drug-Induced Liver Injury Associated with Noni (Morinda citrifolia) Juice and Phenobarbital
}

\author{
Anna Mrzljak ${ }^{a, d}$ Iva Kosuta $^{a}$ Anita Skrtic ${ }^{\text {b, d }}$ \\ Tajana Filipec Kanizaj ${ }^{a, d}$ Radovan Vrhovac ${ }^{c, d}$ \\ Departments of ${ }^{\mathrm{a}}$ Medicine and ${ }^{\mathrm{b}}$ Pathology and Cytology, University Hospital \\ Merkur, 'Department of Medicine, University Hospital Center Zagreb, and \\ ${ }^{\mathrm{d}}$ School of Medicine, University of Zagreb, Zagreb, Croatia
}

\section{Key Words}

Drug-induced liver injury · Herb-induced liver injury · Noni juice · Phenobarbital

\begin{abstract}
Noni (Morinda citrifolia) juice is a popular herbal dietary supplement globally used for preventive or therapeutic purposes in a variety of ailments, claiming to exhibit hepatoprotective properties as well. Herein we present the case of a 38-year-old woman who developed acute liver injury associated with noni juice consumption on a long-term (9 months) anticonvulsant therapy. Clinical presentation and liver biopsy were consistent with severe, predominantly hepatocellular type of injury. Both agents were stopped and corticosteroids were initiated. Five months later the patient had fully recovered. Although in the literature the hepatotoxicity of noni juice remains speculative, sporadic but emerging cases of noni juice-associated liver injury address the need to clarify and investigate potential harmful effects associated with this supplement.
\end{abstract}

\section{Background}

Drug-induced liver injury (DILI) is continuously emerging as a significant cause of liver disease, representing today a leading cause of acute liver failure in Western countries [1,2]. Many conventional drugs, but also the increasingly popular dietary and herbal supplements contribute to this rising equation. This is a reflection of a growing awareness to improve health by adequate nutritional and immunological status, associated with the belief that supplements, mainly derived from plants, do not exhibit toxic effects. One of the most popular dietary supplements in Western countries 
is a noni juice, approved as a novel food by the European Commission in 2003. Morinda citrifolia is a tree in the coffee family (Rubiaceae) with a long history of use in Asian countries as a traditional medicinal plant, claiming to be beneficial in almost every health condition, although scientific evidence of these benefits still remains limited [3-5]. The claimed hepatoprotective properties on noni juice however still remain speculative [6, 7]. Recently, seven cases of Morinda citrifolia-associated liver injury emerged in the literature, emphasizing its possible hepatotoxic effect [8-13].

We present a case of severe drug-herb-induced liver injury that developed in a 38-year-old patient after 7-day consumption of a herbal preparation (noni juice). The patient was also receiving long-term ( 9 months) anticonvulsant therapy (phenobarbital, PB) due to a pathological electroencephalogram. Other possible underlying causes of liver injury, such as biliary or vascular obstruction, viral hepatitis, autoimmune hepatitis, hemochromatosis and Wilson's disease, were ruled out. Five months after discontinuation of both PB and noni juice the patient had fully recovered. Herein we discuss the impact of noni juice and concomitant PB in the context of synergistic drug-herb-induced liver injury, with a review of the literature.

\section{Case Report}

A 38-year-old woman suffering from headache was diagnosed with intracranial aneurysm of the left internal carotid artery and underwent successful surgery in January 2011. She had an unremarkable medical history and was not taking any medication, except for noni juice on several occasions during the past years (to the patient's recollection, she took the juice on three separate occasions during the last 3 years, the recommended daily doses of $60 \mathrm{ml}$ for 2-3 weeks, to 'strengthen her immune system'). Liver tests before operation were unremarkable. Based on pathological electroencephalogram postoperatively, PB was initiated for the prevention of seizures. During 9 months of follow-up, clinical and liver function tests remained unremarkable and the patient started to work. In October 2011, in order to 'improve her energy' the patient started taking the recommended daily doses $(60 \mathrm{ml})$ of noni juice again, and 1 week after she jaundiced.

On admission, laboratory tests showed bilirubin $165.3 \mu \mathrm{mol} / \mathrm{l}$ (normal 2-20), AST $925 \mathrm{U} / \mathrm{l}$ (normal 8-30), alanine aminotransferase (ALT) $813 \mathrm{U} / \mathrm{l}$ (normal 10-36), $\gamma$-glutamyl transpeptidase 933 U/l (normal 9-35), alkaline phosphatase (AP) 532 U/l (normal 54-119) and international normalized ratio 2.61 , indicating hepatocellular injury (ratio $\geq 5$ ) according to the DILI classification [14]. The PB level was below the therapeutic range (77 $\mu \mathrm{mol} / \mathrm{l}$; normal 86-173). Genotyping of CYP2C19 and CYP2C 9 polymorphisms identified CYP2C $9 * 1 /{ }^{*} 1$ and CYP2C $19 * 1 / * 1$, fast metabolic genotypes. There was no evidence of biliary or vascular obstruction on ultrasound. Viral hepatitis (A, B C), cytomegalovirus, Epstein-Barr virus, human immunodeficiency virus, herpes simplex virus, autoimmune hepatitis (anti-nuclear antibody, anti-smooth muscle antibody, anti-liver-kidney microsome antibody), hemochromatosis and Wilson's disease tested negative. The level of bilirubin peaked at $366 \mu \mathrm{mol} / \mathrm{l}$, whereas other liver tests did not deteriorate significantly.

A percutaneous liver biopsy revealed mixed pattern of injury with predominant hepatocellular form (fig. 1). Hepatocellular zonal necrosis mostly in the perivenular zone (zone 3) with massive necrosis of one entire lobule was found accompanied by sinusoidal lymphocytosis. An intrahepatic hepatocanalicular cholestasis with portal tract inflammatory infiltrate rich in eosinophils was obtained. Qualitative histochemical staining of copper and iron was negative. Both PB and noni juice were discontinued. Treatment with steroids was initiated and gradually tapered during 3 months until discontinuation. A control liver biopsy 3 months after discharge revealed preserved architecture of lobules with mild mixed type of sinusoidal inflammation in only one lobule and also mild canalicular type of cholestasis. In the portal tracts mild mixed type of inflammation was found with no signs of ductular type cholestasis (fig. 2). Two months later liver enzymes, bilirubin and international normalized ratio had normalized and the patient remained asymptomatic. 


\section{Conclusions}

The development of liver injury concomitant with the use of conventional drugs or dietary and herbal supplements, even in the presence of preexisting liver disease, rises a suspicion of DILI [15-17]. Since no specific markers of DILI exist, several scoring systems [18-22] have been developed to assess causality in hepatotoxicity, however not without limitations [23]. Therefore the diagnosis of DILI still rests on the identification of a temporal association between drug and liver injury and the exclusion of other conditions [24]. The diagnosis of DILI is especially difficult when multiple agents are involved, since any one of them might be responsible for the injury. Indeed, additive or even synergistic toxic effects of the combination always need to be taken into consideration [25, 26]. Furthermore, except for predictable, dose-dependent type of reaction, DILI may be a result of unpredictable, idiosyncratic, dose-independent reaction which cannot be explained on the basis of the known pathophysiological mechanisms of the drug $[2,27]$. The concept of DILI from conventional drugs had been extensively studied in the literature, however underlying mechanisms of idiosyncratic DILI remain poorly understood. Within this concept, herb-induced liver injury is an emerging entity [28]. In the presented case jaundice appeared after 1 week of noni juice consumption (cumulative amount approximately $400 \mathrm{ml}$ ) in a patient on long-term ( 9 months) PB therapy. Therefore a toxic effect of both drugs as well as their synergistic effect must be suspected.

Individual susceptibility to the anticonvulsant $\mathrm{PB}$ is determined by the pharmacogenetically variable hepatic cytochrome P450 (CYP) enzyme system [29, 30]. However, the fast metabolic genotypes CYP2C $9 * 1 /{ }^{*} 1$ and CYP2C19*1/*1, identified in our patient, did not affect PB metabolism. The clinical pattern of PB-induced hepatotoxicity is a mixed pattern of injury [24], however despite of known hepatotoxic potential, PB has rarely been associated with severe liver injury [9]. In this case, marked elevation of serum ALT $(23 \times \mathrm{ULN})$ and ALT/AP ratio $($ ratio $=6)$ indicated hepatocellular injury. Furthermore, during the long-term treatment with PB only, with serum levels below the therapeutic range, none of the laboratory and clinical features of DILI were noticed. However, according to the Roussel Uclaf Causality Assessment Method scale [23], causality assessment of noni juice in the presented case was probable (score $=6$ ).

So far, in 3 out of 7 cases of noni juice-associated liver injury concomitant therapy was reported: interferon beta [9], Chinese herbal mixture with acetaminophen [10] and levetiracetam [12]. In all cases of noni juice-associated DILI, the pattern of liver injury was hepatocellular with a highly variable time span (1-4 months). Three cases presented with liver failure, of whom one required liver transplantation [10]. Although these cases, like ours, refer to a possible hepatotoxic effect of noni juice, experimental data from animal models support its hepatoprotective properties and show no dose-dependent hepatotoxicity $[6,7]$. However, absence of noni juice dose-dependent hepatotoxicity does not exclude its idiosyncratic form [31]. It is highly speculative that in this case, noni juice was the only causative agent, due to repetitive history of rechallenge with this agent alone. Thus, in the present case the hypothesis rests on synergistic idiosyncratic drug-herb-induced liver injury. Probable hepatotoxic synergism of these agents is further strengthened by the fact of fast occurrence of liver injury after noni juice ingestion. Normalization of liver function tests occurred after 
discontinuation of both agents and induction of corticosteroids. The authors are aware that data regarding the efficacy and safety of corticosteroids in the treatment of DILI are lacking, however in this severe form of DILI they were used as a rescue therapy with positive outcome. Due to the severity of initial liver injury, rechallenge with noni juice and/or PB to assess the causality was not considered.

In conclusion, the spectrum of agents responsible for DILI has been changing due to the increasing popularity of dietary and herbal supplements, consumed alone or in addition to conventional drugs. Moreover, as dietary supplements and over-the-counter drugs may be accessed unrestrictedly in most of the cases, it is very important to be aware of the hepatotoxic potential carried by these supplements. The present case of liver injury associated with noni juice and PB contributes to the emerging literature on this issue and supports the need for a detailed phytochemical profiling of these supplements to provide sufficient data on the chemical composition, with appropriate tools for quality assessment of herbal products and further investigation of underlying mechanisms of drug-herb-induced liver injuries.

\section{Disclosure Statement}

The authors declare that they have no competing interests.
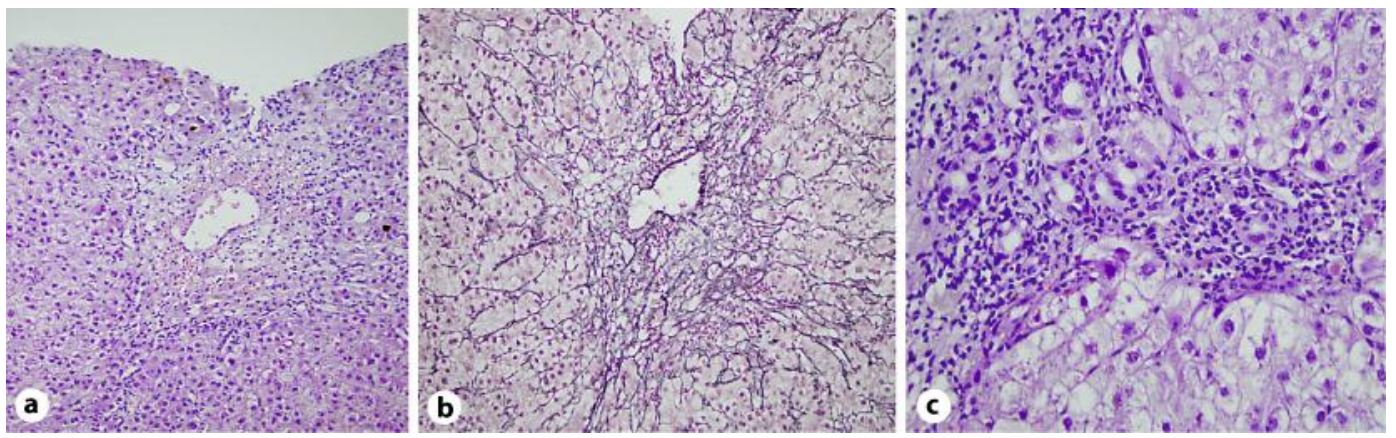

Fig. 1. Percutaneous needle liver biopsy with mixed pattern of injury with predominant hepatocellular form. a Predominant perivenular hepatocellular zonal necrosis with hepatocanalicular cholestasis (HE staining, 200×). b Collapse of the reticular network in the perivenular zone (zone 3) (Gömöri staining, $200 \times$ ). c Portal tract inflammatory infiltration rich in eosinophils (HE staining, 400×). 

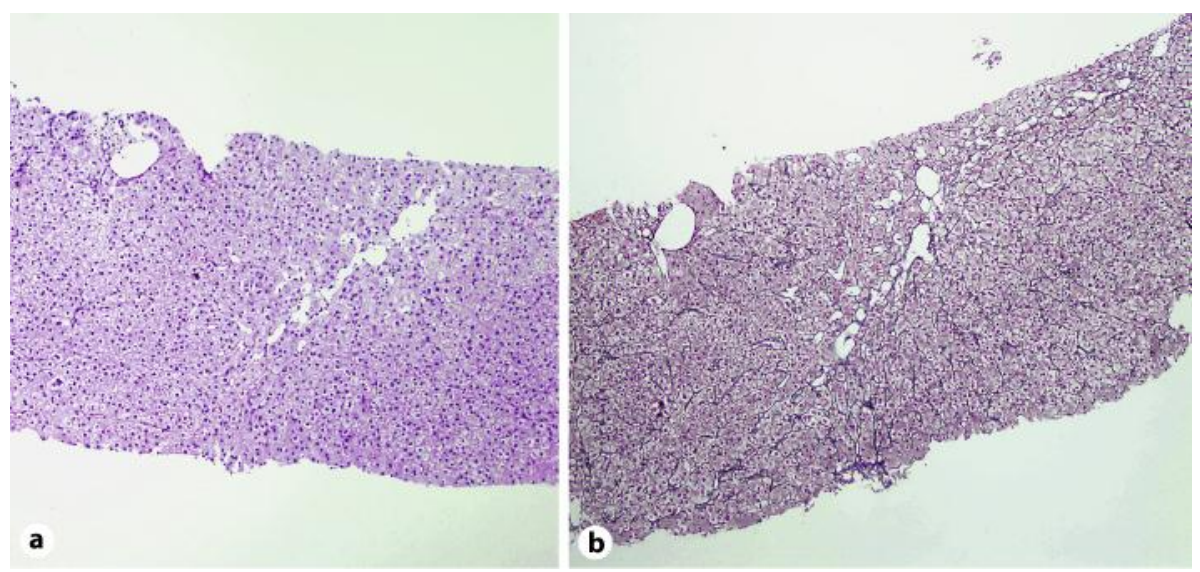

Fig. 2. Control needle liver biopsy. a Preserved architecture of lobuli (HE staining, 200×). b Preserved reticular network (Gömöri staining, 200×).

\section{References}

1 Ostapowicz G, Fontana RJ, Schiødt FV, Larson A, Davern TJ, Han SH, McCashland TM, Shakil AO, Hay JE, Hynan L, Crippin JS, Blei AT, Samuel G, Reisch J, Lee WM: U.S. Acute Liver Failure Study Group: Results of a prospective study of acute liver failure at 17 tertiary care centers in the United States. Ann Intern Med 2002;137:947-954.

-2 Watkins PB, Seeff LB: Drug-induced liver injury: summary of a single topic clinical research conference. Hepatology 2006;43:618-631.

-3 Pawlus AD, Kinghorn AD: Review of the ethnobotany, chemistry, biological activity and safety of the botanical dietary supplement Morinda citrifolia (noni). J Pharm Pharmacol 2007;59:1587-1609.

4 McClatchey W: From Polynesian healers to health food stores: changing perspectives of Morinda citrifolia (Rubiaceae). Integr Cancer Ther 2002;1:110-120.

5 Wang MY, Su C: Cancer preventive effect of Morinda citrifolia (noni). Ann N Y Acad Sci 2001;952: 161-168.

6 Wang MY, Anderson G, Nowicki D, Jensen J: Hepatic protection by noni fruit juice against CCl(4)-induced chronic liver damage in female SD rats. Plant Foods Hum Nutr 2008;63:141-145.

7 West BJ, Su CX, Jensen CJ: Hepatotoxicity and subchronic toxicity tests of Morinda citrifolia (noni) fruit. J Toxicol Sci 2009;34:581-585.

8 Millonig G, Stadlmann S, Vogel W: Herbal hepatotoxicity: acute hepatitis caused by a Noni preparation (Morinda citrifolia). Eur J Gastroenterol Hepatol 2005;17:445-447.

-9 Yuce B, Gulberg V, Diebold J, Gerbes AL: Hepatitis induced by Noni juice from Morinda citrifolia: a rare cause of hepatotoxicity or the tip of the iceberg? Digestion 2006;73:167-170.

10 Stadlbauer V, Fickert P, Lackner C, Schmerlaib J, Krisper P, Trauner M, Stauber RE: Hepatotoxicity of NONI juice: report of two cases. World J Gastroenterol 2005;11:4758-4760.

-11 López-Cepero Andrada JM, Lerma Castilla S, Fernández Olvera MD, Amaya Vidal A: Hepatotoxicity caused by a Noni (Morinda citrifolia) preparation. Rev Esp Enferm Dig 2007;99:179-181.

12 Stadlbauer V, Weiss S, Payer F, Stauber RE: Herbal does not all mean innocuous: the sixth case of hepatotoxicity associated with Morinda citrifolia (noni). Am J Gastroenterol 2008;103:2406-2407.

13 Yu EL, Sivagnanam M, Ellis L, Huang JS: Acute hepatotoxicity after ingestion of Morinda citrifolia (Noni Berry) juice in a 14-year-old boy. J Pediatr Gastroenterol Nutr 2011;52:222-224.

14 Aithal GP, Watkins PB, Andrade RJ, Larrey D, Molokhia M, Takikawa H, Hunt CM, Wilke RA, Avigan M, Kaplowitz N, Bjornsson E, Daly AK: Case definition and phenotype standardization in drug-induced liver injury. Clin Pharmacol Ther 2011;89:806-815.

15 Sgro C, Clinard F, Ouazir K, Chanay H, Allard C, Guilleminet C, Lenoir C, Lemoine A, Hillon P: Incidence of drug-induced hepatic injuries: a French population-based study. Hepatology 2002;36:451-455. 
16 Vuppalanchi R, Liangpunsakul S, Chalasani N: Etiology of new-onset jaundice: how often is it caused by idiosyncratic drug-induced liver injury in the United States? Am J Gastroenterol 2007;102:558-562.

17 Carey EJ, Vargas HE, Douglas DD, Balan V, Byrne TJ, Harrison ME, Rakela J: Inpatient admissions for drug-induced liver injury: results from a single center. Dig Dis Sci 2008;53:1977-1982.

18 Naranjo CA, Busto U, Sellers EM, Sandor P, Ruiz I, Roberts EA, Janecek E, Domecq C, Greenblatt DJ: A method for estimating the probability of adverse drug reactions. Clin Pharmacol Ther 1981;30: 239-245.

19 Bégaud B, Evreux JC, Jouglard J, Lagier G: Imputation of the unexpected or toxic effects of drugs. Actualization of the method used in France. Therapie 1985;40:111-118.

20 Danan G, Benichou C: Causality assessment of adverse reactions to drugs - I. A novel method based on the conclusions of international consensus meetings: application to drug-induced liver injuries. J Clin Epidemiol 1993;46:1323-1330.

21 Benichou C, Danan G, Flahault A: Causality assessment of adverse reactions to drugs - II. An original model for validation of drug causality assessment methods: case reports with positive rechallenge. J Clin Epidemiol 1993;46:1331-1336.

-22 Maria VA, Victorino RM: Development and validation of a clinical scale for the diagnosis of drug-induced hepatitis. Hepatology 1997;26:664-669.

-23 García-Cortés M, Stephens C, Fernández-Castañer A, Lucena MI, Andrade RJ: Causality assessment methods in drug induced liver injury: strengths and weaknesses. J Hepatol 2011;55:683-691.

24 Navarro VJ, Senior JR: Drug-related hepatotoxicity. N Engl J Med 2006;354:731-739.

-25 Bissell DM, Gores GJ, Laskin DL, Hoofnagle JH: Drug-induced liver injury: mechanisms and test systems. Hepatology 2001;33:1009-1013.

26 Liu ZX, Kaplowitz N: Immune-mediated drug-induced liver disease. Clin Liver Dis 2002;6:755-774.

-27 Björnsson E: Review article: drug-induced liver injury in clinical practice. Aliment Pharmacol Ther 2010;32:3-13.

28 Valente G, Sanges M, Campione S, Bellevicine C, De Franchis G, Sollazzo R, Mattera D, Cimino L, Vecchione R, D’Arienzo A: Herbal hepatotoxicity: a case of difficult interpretation. Eur Rev Med Pharmacol Sci 2010;14:865-870.

29 Potterat 0, Hamburger M: Morinda citrifolia (Noni) fruit - phytochemistry, pharmacology, safety. Planta Med 2007;73:191-199.

-30 Wang MY, West BJ, Jensen CJ, Nowicki D, Su C, Palu AK, Anderson G: Morinda citrifolia (Noni): a literature review and recent advances in Noni research. Acta Pharmacol Sin 2002;23:1127-1141.

31 Stickel F, Kessebohm K, Weimann R, Seitz HK: Review of liver injury associated with dietary supplements. Liver Int 2011;31:595-605. 